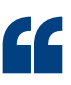

initial prion

conversion

seems to

occur first at

the plasma

membrane

\title{
PRIONS
}

\section{The fast and the furious}

The host cellular prion protein $\left(\mathrm{Pr}^{\mathrm{C}}\right)$ can be converted into the misfolded and infectious scrapie form $\left(\mathrm{PrP}^{\mathrm{sc}}\right)$ when the two forms come into contact, causing prion diseases. By developing a new cell system, this study offers novel insights into how $\mathrm{PrP}^{\mathrm{C}}$ is converted into the misfolded protein.

To study prion conversion in more detail, the authors developed $\mathrm{PrP}^{\mathrm{C}}$ constructs expressing a MYC tag at the carboxyl terminus. These were transfected into a prionsusceptible mouse cell line in which endogenous $\operatorname{PrP}^{\mathrm{C}}$ had been silenced (PrP-224AlaMYC cells). The MYCtagged constructs were expressed at wild-type levels and localized normally, and exposure to prions led to robust conversion into MYC-tagged $\mathrm{PrP}^{\mathrm{Sc}}$. To confirm that the cells were producing infectious prions, extracts were used to infect mice, which subsequently developed neuropathology typical of prion disease.

Previous studies had suggested that de novo-synthesized $\mathrm{PrP}^{\mathrm{Sc}}$ appears within 72 hours (or longer) of exposure to infectious material. Interestingly, the authors show that some PrP-224AlaMYC cells accumulated $\mathrm{PrP}^{\mathrm{Sc}}$ in under 2 hours, and in fact only 1-2 minutes of exposure was enough to lead to conversion. Therefore, conversion is much faster than previously thought.

So where is $\operatorname{PrP}^{\mathrm{Sc}}$ synthesized? The plasma membrane had been suggested as the site of prion conversion, and indeed, in cells exposed to infectious material for just 1 minute, $\mathrm{PrP}^{\mathrm{Sc}}$ was present only on the plasma membrane. However, intracellular $\mathrm{PrP}^{\mathrm{Sc}}$ was observed after 2 minutes of exposure, suggesting that it is rapidly endocytosed and trafficked into the cell. Indeed, the location of $\mathrm{PrP}^{\mathrm{Sc}}$ in the cell was found to depend on the length of exposure, with $\mathrm{PrP}^{\mathrm{Sc}}$ being located exclusively on the plasma membrane at the earliest time-point and distributed inside the cell later on.

To confirm that prion conversion can occur on the plasma membrane, the authors blocked endocytosis; this did not prevent $\mathrm{PrP}^{\mathrm{Sc}}$ formation.
Importantly, $\mathrm{PrP}^{\mathrm{Sc}}$ levels were significantly reduced in PrP-224AlaMYC cells that had been treated with phosphoinositide-specific phospholipase $\mathrm{C}$ or with agents that disrupt lipid raft integrity. Therefore, initial prion conversion seems to occur first at the plasma membrane, perhaps in lipid rafts. However, intracellular compartments may also have a role in this, possibly by accelerating conversion after $\mathrm{PrP}^{\mathrm{Sc}}$ has been endocytosed.

Together, these findings provide new insights into prion conversion by revealing the kinetics and location of $\mathrm{PrP}^{\mathrm{Sc}}$ formation, and may partly explain why prion infections spread throughout the nervous system so quickly.

Rachel David

ORIGINAL RESEARCH PAPER Goold, R. et al Rapid cell-surface prion protein conversion revealed using a novel cell system. Nature Commun. 19 Apr 2011 (doi:10.1038/ ncomms1282)

FURTHER READING Tuite, M. F. \& Serio, T. R. The prion hypothesis: from biological anomaly to basic regulatory mechanism. Nature Rev. Mol. Cell Biol. 11, 823-833 (2010)

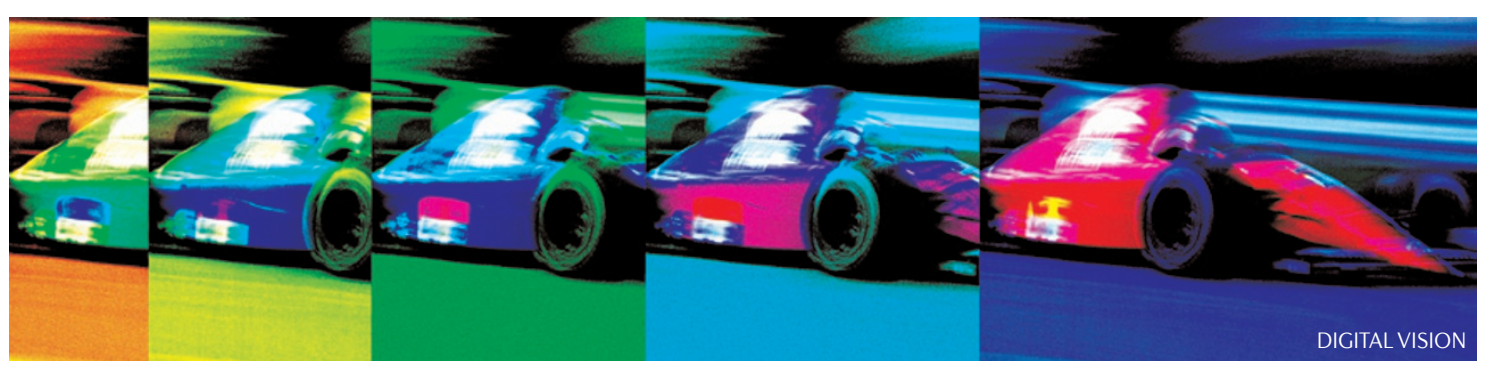

